\title{
Drought Stress Reduces Stem Elongation and Alters Gibberellin-related Gene Expression during Vegetative Growth of Tomato
}

\author{
Alexander G. Litvin', Marc W. van Iersel, and Anish Malladi \\ Department of Horticulture, University of Georgia, 1111 Miller Plant Sciences, Athens, GA 30602
}

\begin{abstract}
AdDitional INDEX wORDs. expansin, GA20ox, GA3ox, GA2ox, EXP1, phytohormones, paclobutrazol
Abstract. Drought stress reduces stem elongation and cell expansion. Since gibberellins (GAs) play an important role in controlling cell elongation, the objective of this study was to determine if the reduction in growth under drought stress is associated with altered GA metabolism or signaling. We exposed 'Moneymaker' tomato (Solanum lycopersicum) to drought stress to observe the effects on growth. Irrigation was automated using a data logger, which maintained volumetric water contents (VWC) of 0.35 and $0.15 \mathrm{~m}^{3} \cdot \mathrm{m}^{-3}$ for well-watered and drought-stressed conditions, respectively. To further investigate the effect of GAs on elongation, paclobutrazol (PAC), a GA biosynthesis inhibitor, was applied to reduce endogenous GA production. Drought stress and PAC treatment reduced plant height. Internode length, cell size, and shoot dry weight displayed an interaction between the VWC and PAC treatments. The transcript levels of SIGA20ox1, -2, -3, and -4 , SlGA3ox2, and SlGA2ox2, -4, and -5 , corresponding to enzymes in GA metabolism, and $L e E X P 1$, and -2 , encoding expansin enzymes related to cell wall loosening necessary for cell expansion, were analyzed. Downregulation of transcript accumulation due to drought stress was observed for $S I G A 20 o x 4, S I G A 2 o x 5$, and LeEXP1, but not for any of the other genes. PAC increased expression of $S I G A 20 o x-3$, and $S I G A 3 o x 2$, potentially through feedback regulation. These findings suggest that drought stress effects on elongation are at least partly mediated by altered GA metabolism.
\end{abstract}

Water availability for agriculture is expected to decrease while drought will likely become more common as a result of climate change (Cook et al., 2015). Water availability affects growth and development throughout a plant's life cycle (Nuruddin et al., 2003), and water shortages reduce agricultural yields globally (Greenwood et al., 2010). A better understanding of drought stress effects on plant growth and development is needed to improve our understanding of how climate change may affect agriculture.

Drought stress can reduce cell division and expansion, nutrient uptake and transport, and alter phytohormone metabolism and signaling, as well as general metabolism in plants (Soroushi et al., 2011). The severity of drought stress often determines the physiological responses of the plant, including its impact on growth (Galmes et al., 2007; Kim et al., 2012). Under mild drought stress, plants may acclimate to maintain metabolic functions. Reductions in stem elongation and photosynthetic rates can result from acclimation, and can intensify with increasing stress (Xu et al., 1997). More intense drought stress may limit a plant's ability to acclimate, resulting in severe plant responses, such as stomatal closure and large reductions in photosynthesis (Kakumanu et al., 2012; Watkinson et al., 2003). Such decreases in metabolism are accompanied by a reduction in growth and are considered as survival mechanisms in response to the severity of the stress (Gong et al., 2010; Huang et al., 2008; Li et al., 2012).

Stem elongation is facilitated by cell division and expansion, and is often a simple and quantitative proxy for a range of drought stress responses (Alem et al., 2015; Hsiao, 1973; Nuruddin et al., 2003). The reduction in elongation becomes more severe as drought stress increases, as reported in Hibiscus acetosella (Bayer et al., 2013), Tagetes patula (van Iersel and

Received for publication 29 Aug. 2016. Accepted for publication 6 Oct. 2016. ${ }^{1}$ Corresponding author. E-mail: alitvin@iastate.edu.
Nemali, 2004), and Euphorbia pulcherrima (Alem et al., 2015). In tomato, reduced stem elongation under drought is associated with shorter internode lengths (Morales et al., 2015).

The reduction in stem elongation under drought stress may result from a reduction in cell division, expansion or both (Campbell, 1974; Farooq et al., 2009; Hsiao, 1973; Massacci et al., 1996). Cell expansion, an increase in cell volume, is very sensitive to drought stress. Reduced cell size is often observed across a range of drought severities (Galmes et al., 2007; Massacci et al., 1996; Zhao et al., 2011). Loosening of the cell wall to increase plasticity and the presence of adequate turgor pressure are key factors that facilitate cell expansion (Cosgrove et al., 2002). Cell wall extensibility is affected by multiple enzymes, including expansins. Expansins increase loosening of the cell wall, potentially by breaking bonds among cellulose microfibrils and/or hemicelluloses, thereby allowing turgor pressure to expand the cell (Cosgrove, 2000, 2015; Keller and Cosgrove 1995). Expansin activity and the expression of genes encoding them can decrease due to drought stress, limiting cell expansion (Zhao et al., 2011). However, mechanisms that facilitate changes in cell expansion in response to drought stress are not completely understood.

Plant growth and development and their responses to environmental stress are mediated by various phytohormones. Gibberellins (GAs) are particularly important for the control of stem elongation through their effects on cell expansion and division (Achard et al., 2009). Symptoms of GA deficiency can appear phenotypically similar to those of drought stress. During prolonged drought, plants display reduced height, leaf development, and flowering/fruit development (Olimpieri et al., 2011). Similarly, a reduction in endogenous GA content results in dwarfed plants with reduced stem elongation, leaf development, aberrant flowering, and fruit set (Vettakkorumakankav et al., 1999). Drought stress reduces the expression of genes involved in GA biosynthesis, thereby reducing the synthesis of 
bioactive GAs (Zeevaart et al., 1993). Gibberellin content can be reduced under drought conditions, leading to a decline in internode elongation in accordance with the severity of GA reduction (Li et al., 2012; Zeevaart et al., 1993). This may offer an adaptive advantage as smaller plants are better able to tolerate and survive drought conditions (Li et al., 2012). Plants with reduced elongation may be more suitable for environments where drought stress occurs frequently (Vettakkorumakankav et al., 1999).

Gibberellin metabolism and signaling are key processes influencing GA-dependent plant growth responses. GA 20oxidases, GA 3-oxidases, and GA 2-oxidases are some of the key enzymes regulating GA metabolism (Hedden and Kamiya, 1997; Hedden and Phillips, 2000; Yamaguchi and Kamiya, 2000). The GA 20-oxidases and GA 3-oxidases act in succession on GA precursors to ultimately generate bioactive GAs, whereas GA 2-oxidases facilitate catabolism of bioactive GAs. DELLA, a key component in GA signaling, acts as a repressor of most GA-related processes including growth (Daviere and Achard, 2013). GAs in turn affect DELLA stability, which is targeted for degradation after bioactive GAs bind to the GA receptor GID1. This relieves the repression of DELLA on downstream GA responses (Hedden and Thomas, 2012; Thomas et al., 2005).

Exogenous application of chemicals that inhibit the activity of enzymes involved in GA biosynthesis can substantially alter plant GA content (Vettakkorumakankav et al., 1999). Paclobutrazol (PAC), a triazole, inhibits ent-kaurene oxidase, reducing its ability to convert ent-kaurene to ent-kaurenoic acid, an important early step in the biosynthesis of GA precursors (Cowling et al., 1998; Vettakkorumakankav et al., 1999). As a result, PAC reduces endogenous production of bioactive GAs (Hedden and Kamiya, 1997; Vettakkorumakankav et al., 1999). Such downregulation of the GA biosynthesis pathway gives rise to phenotypes in tomato that are characterized by stunted growth, small dark wrinkled leaves, and reproductive issues such as sterility (Koornneef et al., 1990). Low GA levels can reduce leaf expansion, and the growth of stem tissue and reproductive organs in tomato (de Moraes et al., 2005; Hafeez-ur-Rahman et al., 1989). These examples further illustrate the strong relationship between GA biosynthesis and plant development.

We hypothesized that drought stress affects plant growth and stem elongation through its interaction with GA metabolism. Hence, the objective of this study was to determine the effects of drought stress on stem elongation and GA metabolismrelated gene expression in tomato plants. To better elucidate the role of GAs in cell expansion and stem elongation in relation to drought, the effect of PAC on gene expression and stem elongation was studied under well-watered and drought conditions.

\section{Materials and Methods}

Plant material and growth conditions. The study was conducted from 23 June until 17 July 2014. Tomato 'Moneymaker' was seeded into $15-\mathrm{cm}$ round pots, grown in a glass greenhouse in Athens, GA. Pots were filled with soilless substrate [70\% peat, 30\% perlite (Fafard 1P; Fafard, Agawam, $\mathrm{MA})$ ] with a $16 \mathrm{~N}-2.6 \mathrm{P}-9.1 \mathrm{~K}$ controlled-release fertilizer (Harrell's 16-6-11; Harrell's, Lakeland, FL) incorporated at a rate of $5.93 \mathrm{~kg} \cdot \mathrm{m}^{-3}$. Initially several seeds were planted in each pot, but were thinned to one seedling per pot after 1 week.
Temperature control in the greenhouse was provided by evaporative cooling, or when necessary, gas heaters and horizontal air flow fans. Temperature and humidity were measured by a data logger (HOBO U12 Temp/RH; Onset, Bourne, MA) inside a radiation shield. Temperature and humidity data were used to calculate vapor pressure deficit (VPD). Photosynthetic photon flux density (PPFD) inside the greenhouse was measured with a quantum sensor (QSO-sun; Apogee Instruments, Logan, UT) connected to a data logger (CR1000; Campbell Scientific, Logan, UT). The cumulative daily PPFD [daily light integral (DLI)] was determined by the data logger. Temperatures averaged $( \pm \mathrm{SD}) 24.5 \pm 2.4{ }^{\circ} \mathrm{C}$, ranging from 19.6 to $32.9^{\circ} \mathrm{C}$. The mean VPD during the study was $0.55 \pm 0.15 \mathrm{kPa}$. DLI ranged from 6.9 to $36.8 \mathrm{~mol} \cdot \mathrm{m}^{2} \cdot \mathrm{d}^{-1}$, averaging $20.3 \pm 7.2 \mathrm{~mol} \cdot \mathrm{m}^{2} \cdot \mathrm{d}^{-1}$.

SubSTRATE volumetric WATER CONTENT. Substrate volumetric water content (VWC) was measured using capacitance sensors (GS3; Decagon Devices, Pullman, WA). Twenty sensors were connected to a data logger (CR1000), and readings from each sensor were used to compute VWC, based on a substrate-specific calibration. Each GS3 sensor was inserted into the pot from the side, placed such that the three prongs of the sensor were vertically aligned down the side of the pot and inserted parallel to the substrate level. Irrigation control was managed using the data logger. A relay driver (SDM-CD16AC controller; Campbell Scientific) operated by the data logger administered valve control. Each of the 20 valves irrigated one experimental unit, with four pots as sub repetitions per valve, and each of the four treatments replicated five times. Each pot was irrigated with a dribble ring (Dramm, Manitowoc, WI) connected to a $2 \mathrm{~L} \cdot \mathrm{h}^{-1}$ pressure-compensating emitter (Netafim USA, Fresno, CA). VWC thresholds for irrigation of 0.35 and $0.15 \mathrm{~m}^{3} \cdot \mathrm{m}^{-3}$, corresponding to well-watered and droughtstressed conditions, were programmed into the data logger to automate irrigation. When VWC for a given experimental unit dropped below its respective threshold, the corresponding irrigation valve was opened for $20 \mathrm{~s}$, providing $11.1 \mathrm{~mL} /$ plant per irrigation cycle. The data logger program ran every $10 \mathrm{~min}$, providing irrigation to individual experimental units on a need basis, up to 144 times per day. The data logger counted the number of irrigation events and those data were used to calculate the total amount of water applied in each experimental unit.

VWC AND PAC TREATMENTS. A total of four different treatments were used in this study; two levels of VWC, each with or without the application of PAC. VWC threshold treatments were initiated on 3 July (day 1) and designated as either well-watered $\left(0.35 \mathrm{~m}^{3} \cdot \mathrm{m}^{-3}\right)$ or drought-stressed $\left(0.15 \mathrm{~m}^{3} \cdot \mathrm{m}^{-3}\right)$. The VWC for the drought treatment was based on preliminary studies. Within each VWC treatment, half the experimental units received $\mathrm{PAC}$, which was applied as a drench at $4 \mathrm{mg}$ a.i. per plant diluted in $2 \mathrm{~mL}$ water on day 1 . All plants were lightly irrigated following PAC application to wash the PAC into the root zone. The rate of PAC application was chosen based on previous reports on stem elongation of tomato (de Moraes et al., 2005; Hafeez-ur-Rahman et al., 1989; Serrani et al., 2007).

Growth MEASUREMENTs. Total height of the plants from the substrate level to the apical meristem and the internode length between the fourth and fifth nodes from the base of the plant were measured for analyses on the final day of the study $(17 \mathrm{~d}$ after treatment). 
For water potential measurements, leaf discs were cut using a 5-mm-diameter biopsy punch (Miltex, York, PA) from fully expanded leaves at $\approx 1200 \mathrm{HR}$ on the final day of the study. The leaf discs were quickly inserted into thermocouple psychrometers (model 76; J.R.D. Merrill Specialty Equipment, Logan, UT), which were then sealed. Samples were temperature equilibrated in a $25^{\circ} \mathrm{C}$ water bath (Neslab RTE-221; Thermo Fisher Scientific, Waltham, MA) for $4 \mathrm{~h}$ before measurement of the psychrometer output with a data logger (CR7X; Campbell Scientific). Samples were then placed in a freezer overnight to disrupt the cellular membranes. Osmotic potential was measured on these samples the following day, after reequilibration in the $25{ }^{\circ} \mathrm{C}$ water bath for $4 \mathrm{~h}$. Each psychrometer was individually calibrated to convert their output to water and $\psi_{\mathrm{S}}$. Turgor pressure within the leaves was then calculated as the difference between water and $\psi_{\mathrm{S}}$. Dry weight of the entire shoots was recorded at the end of the study, after drying for $3 \mathrm{~d}$ in a drying oven at $80{ }^{\circ} \mathrm{C}$.

Microscopy. At the conclusion of the study, the internodes between the fourth and fifth node were harvested for cell size analysis. Harvested internodes were immediately fixed in FAA solution (formaldehyde:acetic acid:ethyl alcohol:water, 10:5:50:35 by volume) (Berlyn and Miksche, 1976). Internode tissue was sliced longitudinally (40-50 $\mu \mathrm{m}$ thick) using a vibratome (Micro-Cut H1200; Bio-Rad, Hercules, CA) and stained with toluidine blue. Immediately after preparation, sections were viewed under a digital microscope (BX51; Olympus Corp., Waltham, MA) and images were obtained for measurement of cell size. Images were analyzed using ImageJ (U.S. National Institutes of Health, Bethesda, MD) to determine cell area. Fifteen individual cells of parenchyma tissue in each image were measured by outlining each cell in ImageJ.

Tissue COllection AND STORAGE. Actively growing internodes, located directly above those used in elongation measurements, were harvested on day 17 at $\approx 1000 \mathrm{HR}$ to determine differences in gene expression among treatments. These internodes were removed using pruning shears and edges cleaned with a razor blade. Samples were immediately placed into $15-\mathrm{mL}$ centrifuge tubes and snap frozen in liquid nitrogen. Samples were then placed in a $-80{ }^{\circ} \mathrm{C}$ freezer and held until further analysis.

IDENTIFICATION OF GIBBERELLIN METABOLISM AND CELL EXPANSION-RELATED GENES. Tomato genes potentially associated with the regulation of later stages of GA metabolism (GA20ox, GA3ox, and GA2ox), GA signaling (DELLA), Actin and Tubulin genes used for normalization of gene expression, and those encoding expansins ( $L e E X P)$ were identified from NCBI Genbank (National Center for Biotechnology Information, Bethesda, MD). These genes correspond to SlGA2ox-2, -4, -5 (NM_001247409, NM_001247818, NM_001247828), SlGA3ox 2 (AB010992), SlGA20ox 1, - 2, - 3, -4 (NM_001247141, NM_001247699, NM_001247650, EU675629), DELLA/GAI (NM_001247436), ACTIN (XM_004235020), TUBULIN (NM_001247878), and LeEXP1, -2 (NM_001247029, AF096776). PCR primers were designed for selected genes (Supplemental Table 1) using the NCBI Nucleotide Primer Blast tool (Blast).

RNA EXtraction, COMPLEMENTARY DNA (CDNA) SYNTHESIS, AND QUANTITATIVE RT-PCR. Tissue samples were ground in liquid nitrogen, and total RNA was extracted using the E.Z.N.A. Plant RNA Mini Kit following manufacturer's protocol (Omega Bio-Tek, Norcross, GA). Total RNA was eluted in $8 \mu \mathrm{L}$ of diethylpyrocarbonate-treated water and quantified using a spectrophotometer (NanoDrop 8000; Thermo Fisher Scientific). The samples were stored at $-80{ }^{\circ} \mathrm{C}$ until cDNA synthesis.

Total RNA $(1 \mu \mathrm{g})$ from each sample was used for cDNA synthesis following the protocol of Malladi and Hirst (2010). Genomic DNA contamination was removed with DNase (Promega, Madison, WI). The cDNA synthesis was performed using oligo dT primers and reverse transcriptase (ImProm II; Promega). The cDNA was diluted 6-fold, and stored at $-20{ }^{\circ} \mathrm{C}$. Gene expression was analyzed by qRT-PCR (Stratagene Mx3005P PCR; Agilent Technologies, Santa Clara, CA). Diluted primers specific to the genes were used along with the SYBR green master mix (Applied Biosystems, Foster City, CA). Amplification and normalization of data followed previous protocols (Dash and Malladi 2012). Gene expression was normalized to that of $A C T I N$ and TUBULIN genes and then $\log 2$ transformed before statistical analysis.

EXPERIMENTAL DESIGN AND STATISTICAL ANALYSIS. A randomized complete block design with four treatments (two VWC levels, with and without PAC application) and five blocks was used. Each experimental unit had four subsamples (individual plants). Data collected from subsamples for height, internode, and shoot dry weight were averaged before analysis. Data were analyzed using analysis of variance $(\alpha=0.05)$ in SAS [PROC ANOVA (SAS version 9.4, SAS Institute, Cary, NC)]. In the event of missing data, data were analyzed using a general linear model in SAS (PROC GLM). Tukey's honest significant difference was subsequently used for mean separation. Linear regression analysis was conducted to analyze correlations among measured variables.

\section{Results and Discussion}

VWC treatments were initiated on 3 July (day 1) and plants under drought stress reached their VWC thresholds of $0.15 \mathrm{~m}^{3} \cdot \mathrm{m}^{-3}$ by $10 \mathrm{~d}$ after treatment. Over the course of the study, irrigation volume averaged $1431 \pm 174 \mathrm{~mL} /$ plant for the control (wellwatered), and $111 \pm 66 \mathrm{~mL} /$ plant for the drought-stressed plants. Treatment with PAC resulted in no significant differences in water use.

MoRPHOLOGICAL EFFECTS. Total plant height was reduced by both drought stress $(P=0.001)$ and PAC $(P<0.0001)$, but the interaction between PAC treatment and VWC was not significant. This is consistent with previous findings that elongation is reduced by decreasing water availability and by inhibitors of GA production (Alem et al., 2015; Burnett et al., 2005; de Moraes et al., 2005). Drought stress and PAC reduced plant height by 2.4 and $7.1 \mathrm{~cm}$, respectively (Fig. 1A). There was an interactive effect of substrate VWC and PAC on internode length $(P<0.001)$. Drought stress reduced internode length of the non-PAC-treated plants by $8.2 \mathrm{~mm}$ and in PAC-treated plants by $1.5 \mathrm{~mm}$ (Fig. 1B). Under both well-watered and drought stress conditions, PAC reduced plant height by $\approx 45 \%$, and internode elongation by $\approx 65 \%$, consistent with previous reports (de Moraes et al., 2005; Hafeez-ur-Rahman et al., 1989).

Drought and PAC had an interactive effect on cell size of growing internodes $(P=0.007)$. Drought stress reduced cell size of plants not treated with PAC by $62 \%$, but had no significant effect on cell size of plants treated with PAC (Fig. 1C). The effect of PAC was likely so pronounced in limiting cell size that drought stress had little to no additional effect. 


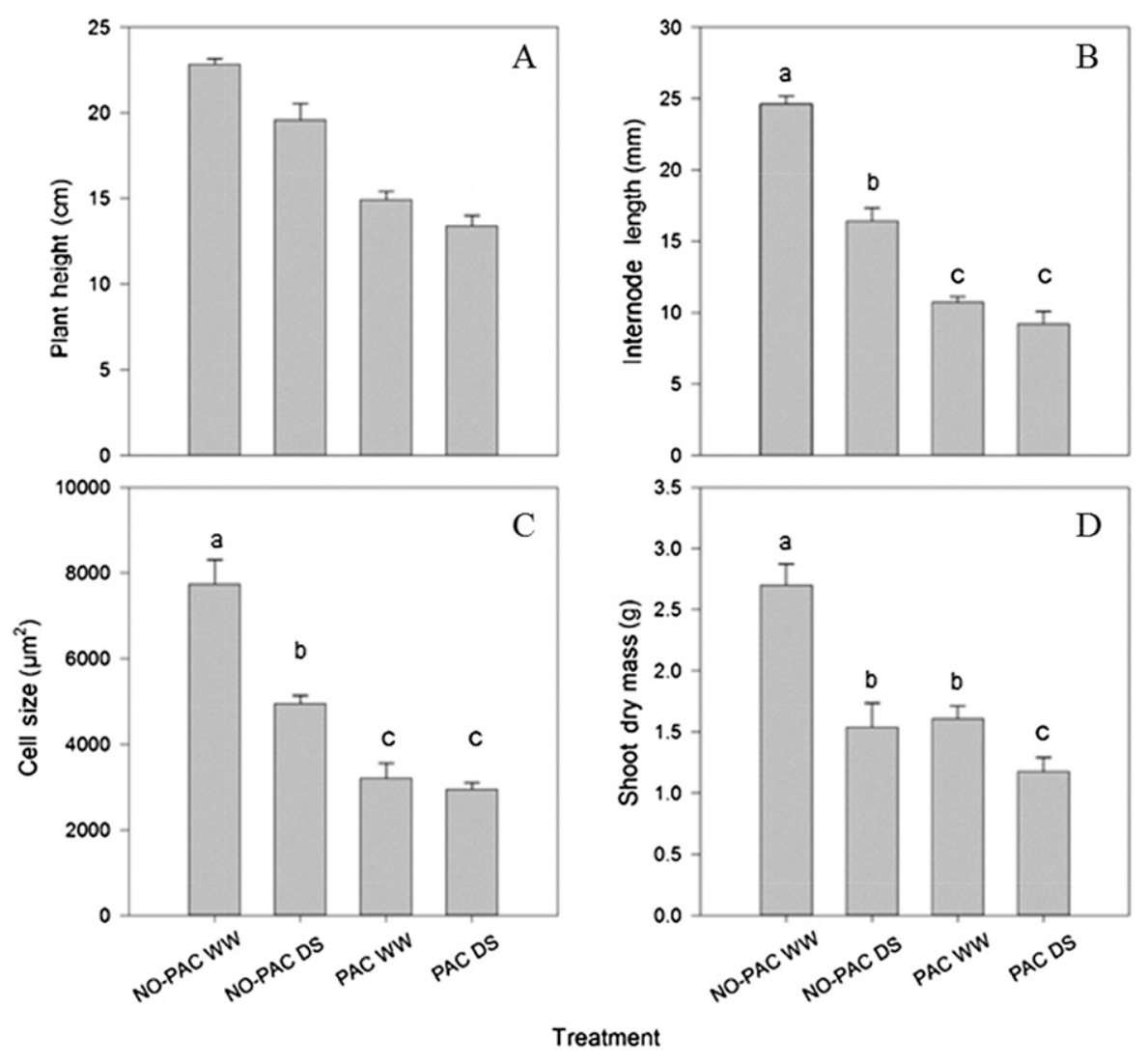

Fig. 1. (A) Plant height, (B) internode length, (C) cell size, and (D) shoot dry weight of tomato plants as affected by well-watered (WW) vs. drought-stressed (DS) conditions, for plants that were treated with paclobutrazol (PAC) or not treated (NO-PAC). For variables with significant interactions between substrate volumetric water content and PAC treatments, means were separated using Tukey's honestly significant difference. Means with the same letter are not significantly different $(P=0.05)$. Plant height was reduced by both drought and PAC application, but not by the interaction between them.

Cell size, internode length, and plant height were strongly and positively correlated (Fig. 2A and 2B), further demonstrating interrelationships among these parameters (Schouten et al., 2002). Cell size is a key component of stem elongation (Huber et al., 2014; Pearson et al., 1995). The phenotypic parameters, plant height and internode length, are determined at the cellular level by the growth-related responses of individual cells to metabolic and environmental conditions (Huber et al., 2014; Nuruddin et al., 2003).

Water (average of $-0.42 \mathrm{MPa})$, osmotic $(-0.88 \mathrm{MPa})$, and turgor potential $(0.46 \mathrm{MPa})$ were not significantly affected by drought or PAC. The lack of an effect of drought stress was unexpected, since water, osmotic, and turgor potential were previously reported to be decreased under drought (Chartzoulakis et al., 2002; Naor et al., 1995; O’Neil, 1983). High coefficients of variation $(>19.8 \%)$ in the data may have contributed to the lack of significant differences. It is also important to consider that these data were collected at the end of the study and may not be representative of plant water status throughout the study. Drought stress induces a multitude of changes in gene expression in tomato (Gong et al., 2010), which can help the plants acclimate to or tolerate drought. It is also important to realize that the type of drought stress used in this study is different from a typical drought under field conditions. We allowed the substrate VWC to drop to $0.15 \mathrm{~m}^{3} \cdot \mathrm{m}^{-3}$, after which the plants were irrigated just enough to maintain that
VWC. Thus, any water used by the plants after the VWC threshold was reached was replenished, whereas under field conditions the amount of soil water continues to decrease during a drought.

PAC application and VWC treatments had an interactive effect on shoot dry weight $(P=0.024)$. Wellwatered plants without PAC had significantly higher shoot dry weight than other plants; droughtstressed, PAC-treated plants had the lowest shoot dry weight. No significant difference was observed between the drought-stressed plants not treated with PAC and wellwatered PAC-treated plants (Fig. 1D). As previously reported, plant size and mass can be reduced by the effect of limited water availability inhibiting cell division and elongation (Farooq et al., 2009; Hsiao, 1973), and PAC further exaggerates this effect by impacting GA metabolism (de Moraes et al., 2005).

EXPRESSION OF GA BIOSYNTHESISRELATED GENES. GA20-oxidases catalyze the synthesis of the precursors of bio-active GAs (Hedden and Phillips, 2000; Li et al., 2012). SlGA20ox 1 and SlGA20ox 2 showed no significant differences in transcript accumulation among treatments, but drought stress downregulated the accumulation of SlGA20ox 4 transcripts by $48 \%[P=0.019$ (Fig. 3A)]. Lower transcript levels of SIGA20ox4 in response to drought stress suggest a role for this gene in regulating plant responses to drought. Downregulation of SlGA20ox4 expression in response to drought stress can suppress GA-biosynthesis and reduce internode elongation in tomato ( $\mathrm{Li}$ et al., 2012). This downregulation of SIGA20ox4 expression limiting bioactive GA content was proposed to be part of a drought tolerance mechanism mediated by a transcription factor, SIDREB (Li et al., 2012).

SlGA200x3, another gene within the same family, displayed a 5.5-fold upregulation in transcript levels in response to PAC $(P<0.0001)$. GA3-oxidases catalyze the synthesis of bio-active GAs by acting upon the precursors generated through GA20oxidase activity. SlGA3ox2, a member of a gene family encoding GA3-oxidases, displayed up to a 4-fold upregulation in transcript accumulation in response to PAC $[P=0.003$ (Fig. 3B)]. A strong, positive correlation between SlGA20ox3 and SlGA3ox2 transcript levels was observed $\left[r^{2}=0.69, P<0.001\right.$ (data not shown)] and may be due in part to coregulation of these genes (Hedden and Kamiya, 1997; Hedden and Phillips, 2000; Hedden and Thomas, 2012). The upregulation of SlGA20ox3 and SlGA3ox2 transcript accumulation following PAC application may suggest feedback upregulation of GA biosynthesis in response to low endogenous GA content caused by PAC-induced ent-kaurene oxidase inhibition (Hedden and 

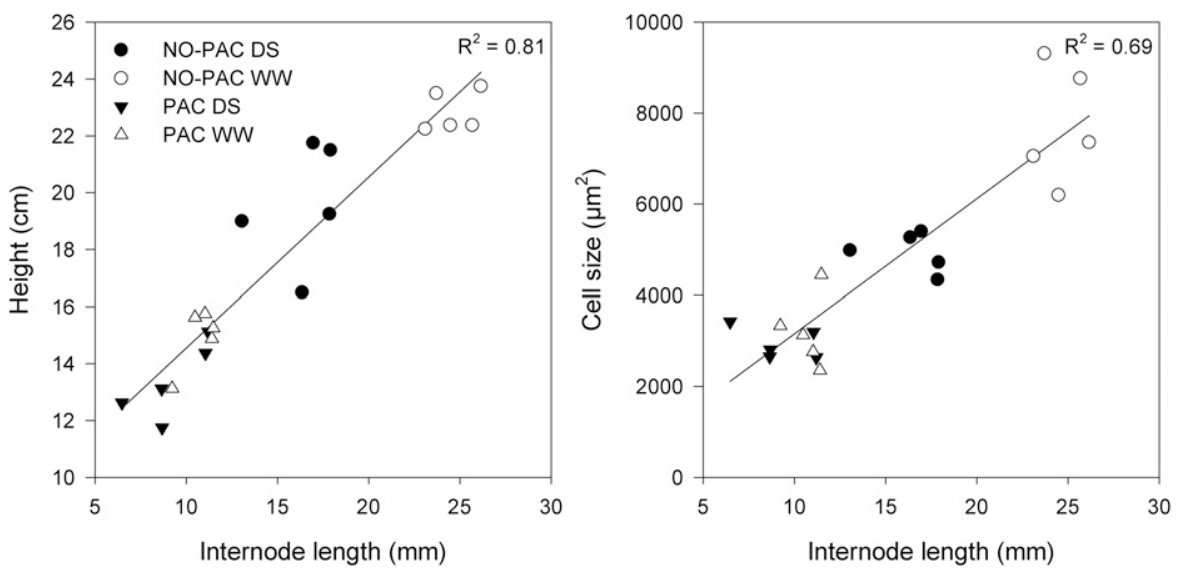

Fig. 2. Correlations among morphological parameters in tomato stem tissue: (A) plant height vs. internode length and (B) internode length vs. parenchyma cell size. Plants were exposed to two levels of drought treatments: wellwatered (WW) and drought-stressed (DS), and two levels of paclobutrazol (PAC) treatment: with paclobutrazol (PAC) and without it (NO-PAC).
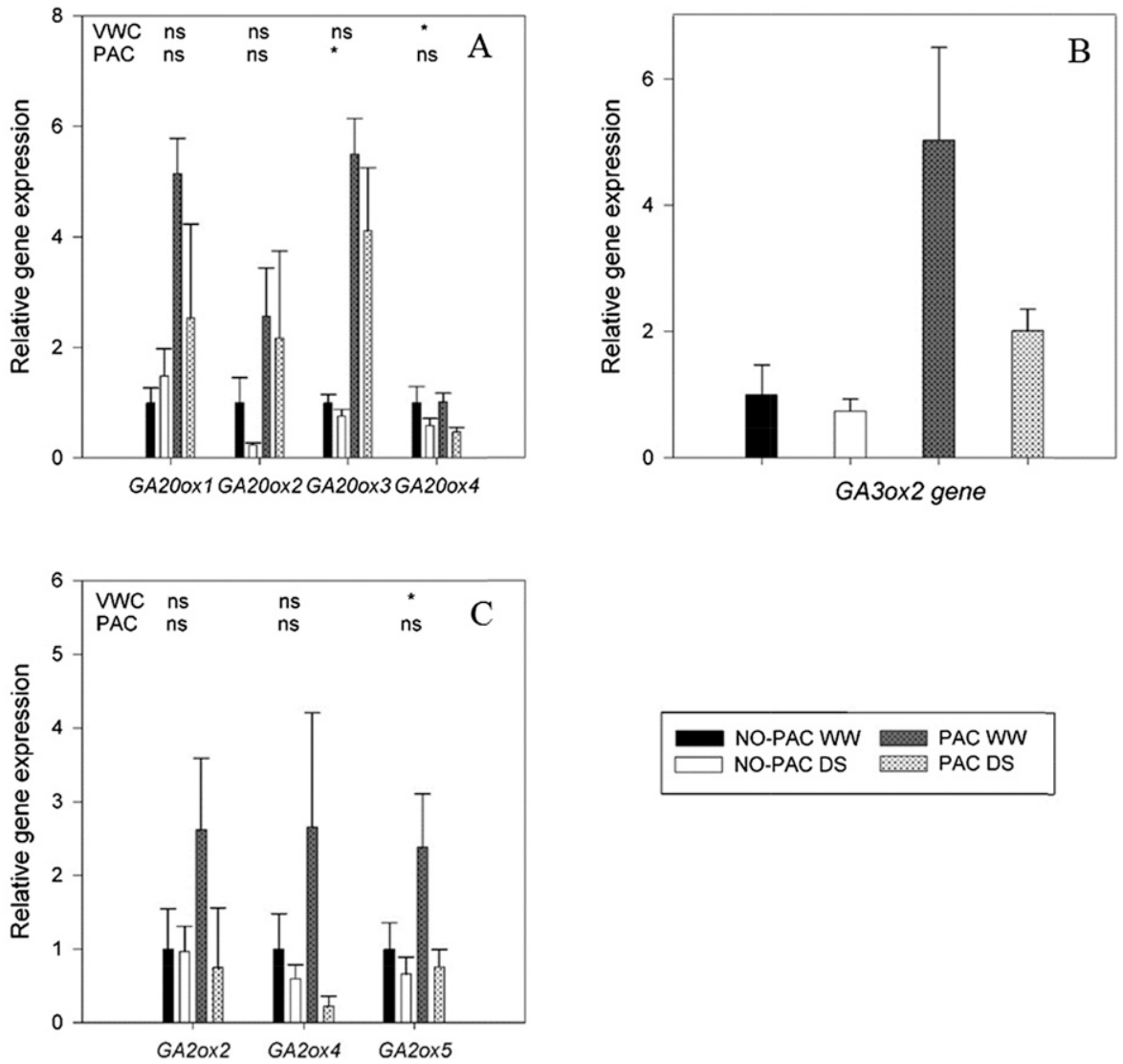

Fig. 3. Expression of genes related to GA metabolism in tomato internodes in response to drought stress or paclobutrazol application for gene families (A) GA20ox, (B) GA3ox, and (C) GA2ox; WW = well-watered, DS = drought-stressed, $\mathrm{PAC}=$ paclobutrazol drench, NO-PAC $=$ no paclobutrazol. Expression of a given gene is relative to transcript levels under NO-PAC, WW conditions. Asterisks $\left(^{*}\right)$ above a specific gene indicate significant effects of drought or PAC $(P<0.05)$; ns $=$ not significant. GA3ox2 was significantly affected by PAC application, but not by drought. There were no significant interactions between drought and PAC treatment.

Thomas, 2012; Rebers et al., 1999; Vettakkorumakankav et al., 1999). These data suggest that the above genes are involved in GA homeostasis.

Catabolism of bioactive GAs is catalyzed by GA2-oxidases, encoded by multiple members of the GA2Ox gene family.
Transcript levels of none of the three GA2ox genes tested in this study were affected by PAC application or by the interaction between PAC and drought. SlGA2ox5 transcript accumulation was downregulated by $51 \%$ under drought stress $[P=0.025$ (Fig. 3C)]. Drought stress has previously been reported to upregulate the expression of several members of the GA2ox family, presumably enhancing the catabolism of bioactive GAs (Zawaski and Busov, 2014; Zhou and Underhill, 2015). However, it should be noted that not all members of this family responded similarly to drought stress (Zawaski and Busov, 2014). Also, a recent study in Brachypodium distachyon indicated a downregulation of a GA2ox gene in response to drought (Verelst et al., 2013), similar to the data presented here. The physiological significance of such downregulation of GA2ox 5 is not clear, and warrants further study. It is possible that additional genes in the GA2ox family, GA2ox 1 and GA2ox3 which belong to a different sub-group (Serrani et al., 2007) and were not studied here, display patterns of expression divergent from that of the three genes studied here. DELLA, a key gene involved in GA signaling, displayed no significant differences in transcript accumulation across all treatments (data not shown).

Different responses to drought or PAC treatment of genes within the same family (e.g., GA20ox), as seen in this study, may be due to different roles of these genes in response to various conditions; e.g., responses to drought appear to involve SlGA20ox4, while SlGA20ox3 may be associated with GA homeostasis. Different genes within the same family may also be involved in differentially regulating responses within specific tissues, allowing for fine tuning of plant responses. It is thus not surprising that the different genes within the same family show dissimilar responses to external stimuli (Hedden and Thomas, 2012; Li et al., 2012).

EXPANSIN GENE EXPRESSION. EXpansins facilitate stem elongation, and tissue and leaf expansion (Caderas et al., 2000; Reinhardt et al., 1998; Van Volkenburgh, 1999), as well as the expansion or softening of cells in other organs such as fruit (Cosgrove et al., 2002; Powell et al., 2003; Rose et al., 1997). 
Both Expansin genes analyzed in this study, LeEXP1 and $L e E X P 2$, were expressed in actively growing shoots (Fig. 4), but only LeEXP1 transcript accumulation was downregulated (by 33\%) in response to drought stress $(P=0.004)$. Transcript levels of neither gene were significantly affected by PAC or the interaction between PAC and drought. Downregulation of expansin gene expression in response to drought was also reported in Triticum aestivum (Zhao et al., 2011). These data suggest that LeEXP1 is involved in regulation of cell expansion in internodes in response to water availability. Together, these data suggest that the reduction in internode cell size in response to drought stress may be mediated by a decline in expansin levels and activity.

\section{Conclusions}

The current study confirmed that cell expansion and consequently internode and stem elongation are reduced in response to drought stress. The effect of drought was generally greater in non-PAC-treated plants than in PAC-treated plants, presumably due to the strong influence of reduced GA content on elongation. Our results highlight the importance of GA metabolism in mediating drought responses, especially in relation to cell expansion and internode elongation. Specifically, SlGA20ox4, which encodes a GA20-oxidase involved in the later stages of the GA biosynthesis pathway, was downregulated in response to drought stress, demonstrating the relationship between GA metabolism and drought. We speculate that decreased GA content as a result of SIGA20ox4 downregulation mediates the decrease in cell elongation and subsequently, internode length.

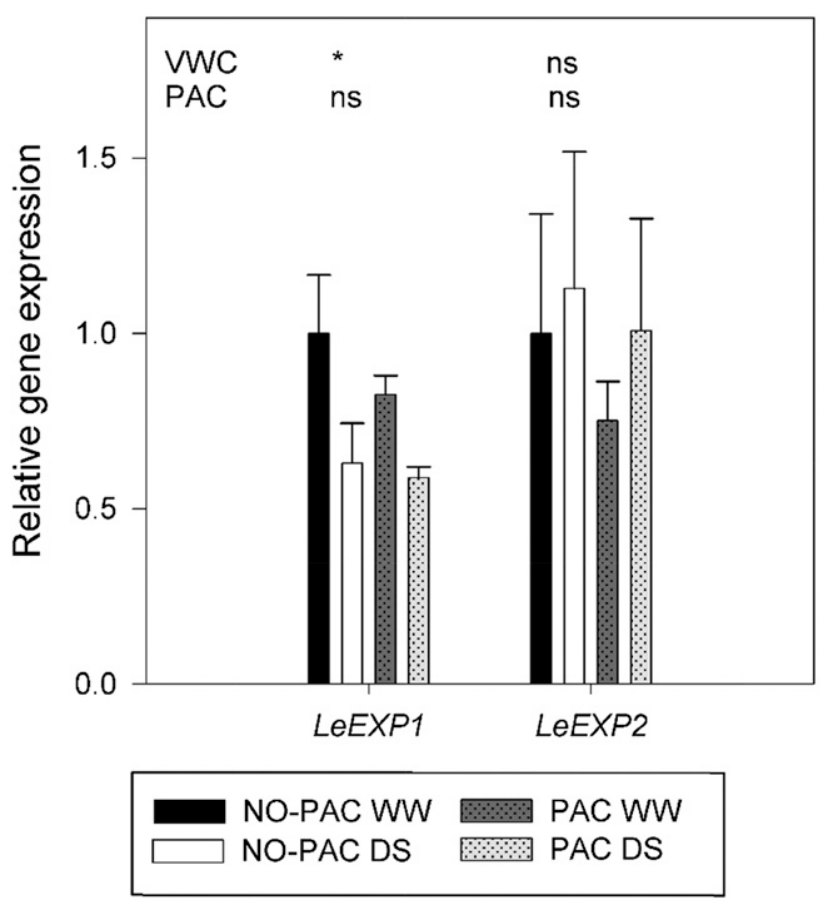

Fig. 4. Expression of two Expansin genes in tomato internodes in response to drought stress or paclobutrazol application; WW $=$ well-watered, DS = drought-stressed, PAC $=$ paclobutrazol drench, NO-PAC $=$ no paclobutrazol. Expression is shown relative to that in the NO-PAC WW treatment. An asterisk $(*)$ above a specific gene indicates a significant effect of drought or PAC $(P<0.05)$; NS $=$ not significant. There were no significant interactions between drought and PAC treatment.
Drought-stressed plants also displayed downregulated expression of LeEXP1 which likely mediates the reduction in cell elongation. Whether the decline in LeEXP1 transcript accumulation is associated with altered GA metabolism and/or signaling, needs to be investigated further. Paclobutrazol application, on the other hand, resulted in increased transcript levels of GAmetabolism-related genes $S l G A 20$ ox 3 and $S l G A 3 o x 2$, possibly as a feedback response to lowered endogenous GA levels. Together, data from this study indicate that reduction in growth under drought stress may be mediated by altered GA metabolism and reduced cell wall loosening. Further characterization of genes involved in the above processes may lead to the development of tomato genotypes with growth characteristics better suited to tolerate drought stress.

\section{Literature Cited}

Achard, P., A. Gusti, S. Cheminant, M. Alioua, S. Dhondt, F. Coppens, G.T.S. Beemster, and P. Genschik. 2009. Gibberellin signaling controls cell proliferation rate in Arabidopsis. Curr. Biol. 14:1188-1193.

Alem, P., P.A. Thomas, and M.W. van Iersel. 2015. Controlled water deficit as an alternative to plant growth retardants for regulation of poinsettia stem elongation. HortScience 50:565-569.

Bayer, A., I. Mahbub, M. Chappell, J. Ruter, and M.W. van Iersel. 2013. Water use and growth of Hibiscus acetosella 'Panama Red' grown with a soil moisture sensor-controlled irrigation system. HortScience 48:980-987.

Berlyn, G.P. and J.P. Miksche. 1976. Botanical microtechnique and cytochemistry. Iowa State Univ. Press, Ames, IA.

Burnett, S.E., S.V. Pennisi, P.A. Thomas, and M.W. van Iersel. 2005. Controlled drought affects morphology and anatomy of Salvia splendens. J. Amer. Soc. Hort. Sci. 130:775-781.

Caderas, D., M. Muster, H. Vogler, T. Mandel, J.K.C. Rose, S. McQueen-Mason, and C. Kuhlemeir. 2000. Limited correlation between expansin gene expression and elongation growth rate. Plant Physiol. 123:1399-1413.

Campbell, J.B. 1974. Effects of cell division and cell length on stem elongation of Liquidamber styraciflua L. seedlings grown under various environments. MS Thesis, Univ. Georgia, Athens.

Chartzoulakis, K., A. Patakas, G. Kofidis, A. Bosabalidis, and A. Nastou. 2002. Water stress affects leaf anatomy, gas exchange, water relations and growth of two avocado cultivars. Sci. Hort. 95:39-50.

Cook, B.I., T.R. Ault, and J.E. Smerdon. 2015. Unprecedented 21st century drought risk in the American southwest and central plains. Sci. Adv. 1:1-7.

Cosgrove, D.J. 2000. Loosening of plant cell walls by expansins. Nature 407:321-326.

Cosgrove, D.J. 2015. Plant expansins: Diversity and interactions with plant cell walls. Curr. Opin. Plant Biol. 25:162-172.

Cosgrove, D.J., L.C. Li, H. Cho, S. Hoffmann-Benning, R.C. Moore, and D. Blecker. 2002. The growing world of expansins. Plant Cell Physiol. 43:1436-1444.

Cowling, R., Y. Kamiya, H. Seto, and N. Harberd. 1998. Gibberellin dose-response regulation of GA4 gene transcript levels in arabidopsis. Plant Physiol. 117:1195-1203.

Dash, M. and A. Malladi. 2012. The AINTEGUMENTA genes, MdANT1 and MdANT2, are associated with the regulation of cell production during fruit growth in apple (Malus $\times$ domestica Borkh.). BMC Plant Biol. 12(98):1-15.

Daviere, J.M. and P. Achard. 2013. Gibberellin signaling in plants. Development 140:1147-1151.

de Moraes, P.J., J.A.S. Grossi, S. de Araujo Tinoco, D.J. Henriques da Silva, P.R. Cecon, and J.G. Barbosa. 2005. Ornamental tomato growth and fruiting response to paclobutrazol. Acta Hort. 683:327-332.

Farooq, M., A. Wahid, N. Kobayashi, D. Fujita, and S.M.A. Basra. 2009. Plant drought stress: Effects, mechanisms and management. Agron. Sustain. Dev. 29:185-212. 
Galmes, J., A. Abadia, H. Medrano, and J. Flexas. 2007. Photosynthesis and photoprotection responses to water stress in the wild-extinct plant Lysimachia minoricensis. Environ. Expt. Bot. 60:308-317.

Gong, P., J. Zhang, H. Li, C. Yang, C. Zhang, X. Zhang, Z. Khurram, Y. Zhang, T. Wang, Z. Fei, and Z. Ye. 2010. Transcriptional profiles of drought-responsive genes in modulating transcription signal transduction, and biochemical pathways in tomato. J. Expt. Bot. 61:3563-3575.

Greenwood, D.J., K. Zhang, H.W. Hilton, and A.J. Thompson. 2010. Opportunities for improving irrigation efficiency with quantitative models, soil water sensors and wireless technology. J. Agr. Sci. 148:1-16.

Hafeez-ur-Rahman, M., A. Khan, and K.M. Khokhar. 1989. Effect of paclobutrazol on growth and yield of tomato. Pakistan J. Agr. Res. $10: 49-52$.

Hedden, P. and A. Phillips. 2000. Gibberellin metabolism: New insights revealed by the genes. Trends Plant Sci. 5:523-530.

Hedden, P. and S. Thomas. 2012. Gibberellin biosynthesis and its regulation. Biochem. J. 444:11-25.

Hedden, P. and Y. Kamiya. 1997. Gibberellin biosynthesis: Enzymes, genes and their regulation. Annu. Rev. Plant Physiol. Plant Mol. Biol. 48:431-460.

Hsiao, T.C. 1973. Plant responses to water stress. Annu. Rev. Plant Physiol. 24:519-570.

Huang, D., W. Wu, S.R. Abrams, and A.J. Cutler. 2008. The relationship of drought-related gene expression in Arabidopsis thaliana to hormonal and environmental factors. J. Expt. Bot. 59:2991-3007.

Huber, H., J. De Brouwer, E. Von Wettberg, H. During, and N. Anten. 2014. More cells, bigger cells or simply reorganization? Alternative mechanisms leading to changed internode architecture under contrasting stress regimes. New Phytol. 20:193-204.

Kakumanu, A., M.M. Ambavaram, C. Klumas, A. Krishnan, U. Batlang, E. Myers, R. Grene, and A. Pereira. 2012. Effects of drought on gene expression in maize reproductive and leaf meristem tissue revealed by RNA-Seq. Plant Physiol. 160:846-867.

Keller, E. and D.J. Cosgrove. 1995. Expansins in growing tomato leaves. Plant J. 8:795-802.

Kim, J., A. Malladi, and M.W. van Iersel. 2012. Physiological and molecular responses to drought in petunia: The importance of stress severity. J. Expt. Bot. 63:6335-6345.

Koornneef, M., T.D.G. Bosma, C.J. Hanhart, J.H. Van Der Veen, and J.A.D. Zeevaart. 1990. The isolation and characterization of gibberellin-deficient mutants in tomato. Theor. Appl. Genet. 80:852-857.

Li, J., W. Sima, B. Ouyang, T. Wang, K. Ziaf, Z. Luo, L. Liu, H. Li, M. Chen, Y. Huang, Y. Feng, Y. Hao, and Z. Ye. 2012. Tomato SIDREB gene restricts leaf expansion for internode elongation by downregulating key genes for gibberellin biosynthesis. J. Expt. Bot. 63:6407-6420.

Malladi, A. and P.M. Hirst. 2010. Increase in fruit size of a spontaneous mutant of 'Gala' apple (Malus $\times$ domestica Borkh.) is facilitated by altered cell production and enhanced cell size. J. Expt. Bot. 61:30033013.

Massacci, A., A. Battistelli, and F. Loreto. 1996. Effect of drought stress on photosynthetic characteristics, growth and sugar accumulation of field-grown sweet sorghum. Austral. J. Plant Physiol. 23:331-340.

Morales, R.G.F., L.V. Resende, I.C. Bordini, A.G. Galvao, and F.C. Rezende. 2015. Characterization of tomato plants subjected to water deficit. Scientia Agraria 16:9-17.

Naor, A., I. Klein, and I. Daron. 1995. Stem water potential and apple size. J. Amer. Soc. Hort. Sci. 120:577-582.

Nuruddin, M.M., C.A. Madramootoo, and G.T. Dodds. 2003. Effects of water stress on tomato at different growth stages. HortScience 38:1389-1393.

O’Neil, S. 1983. Role of osmotic potential gradients during water stress and leaf senescence in Fragaria virginiana. Plant Physiol. 72:931-937.
Olimpieri, I., R. Caccia, M.E. Picarella, A. Pucci, E. Santangelo, G.P. Soressi, and A. Mazzucato. 2011. Constitutive co-suppression of the GA 20-oxidase1 gene in tomato leads to severe defects in vegetative and reproductive development. Plant Sci. 180:496-503.

Pearson, S., P. Hadley, and A.E. Wheldon. 1995. A model of the effect of day and night temperatures on the height of chrysanthemum. Acta Hort. 378:71-80.

Powell, A.L.T., M.S. Kalamaki, P.A. Kurien, S. Gurrieri, and A.B. Bennett. 2003. Simultaneous transgenic suppression of LePG and LeExp1 influences fruit texture and juice viscosity in a fresh market tomato variety. J. Agr. Food Chem. 51:7450-7455.

Rebers, M., T. Kaneta, H. Kawaide, S. Yamaguchi, Y.Y. Yang, R. Imai, H. Sekimoto, and Y. Kamiya. 1999. Regulation of gibberellin biosynthesis genes during flower and early fruit development of tomato. Plant J. 17:241-250.

Reinhardt, D., F. Wittwer, T. Mandel, and C. Kuhlemeier. 1998. Localized upregulation of a new expansin gene predicts the site of leaf formation in the tomato meristem. Plant Cell 10:1427-1437.

Rose, J.K.C., H.H. Lee, and A.B. Bennett. 1997. Expression of a divergent expansin gene is fruit-specific and ripening-regulated. Proc. Natl. Acad. Sci. USA 94:5955-5960.

Schouten, R.E., S. Carvalho, E. Heuvelink, and O. van Kooten. 2002. Modelling of temperature-controlled internode elongation applied to chrysanthemum. Ann. Bot. 90:353-359.

Serrani, J., R. Sanjuan, O. Ruiz-Rivero, M. Fos, and J.L. GarciaMartinez. 2007. Gibberellin regulation of fruit set and growth in tomato. Plant Physiol. 145:246-257.

Soroushi, H., T.S. Nejad, A. Shoukofar, and M. Soltani. 2011. The interaction of drought stress and gibberellic acid on corn (Zea mays L.). World Acad. Sci. Eng. Technol. 60:142-143.

Thomas, S.G., I. Rieu, and C.M. Steber. 2005. Gibberellin metabolism and signaling. Vitam. Horm. 72:289-338.

Van Volkenburgh, E. 1999. Leaf expansion: An integrating plant behavior. Plant Cell Environ. 22:1463-1473.

van Iersel, M.W. and K.S. Nemali. 2004. Drought stress can produce small but not compact marigolds. HortScience 39:1298-1301.

Verelst, W., E. Bertolini, S. De Bodt, K. Vandepoele, M. Demeulenaere, M.E. Pe, and D. Inze. 2013. Molecular and physiological analysis of growth-limiting drought stress in Brachypodium distachyon leaves. Mol. Plant 6:311-322.

Vettakkorumakankav, N., D. Falk, P. Saxena, and R.A. Fletcher. 1999. A crucial role for gibberellins in stress protection of plants. Plant Cell Physiol. 40:542-548.

Watkinson, J.I., A. Sioson, C. Vasquez-Robinet, M. Shukla, D. Kumar, M. Ellis, L.S. Heath, N. Ramakrishan, B. Chevone, L.T. Watson, L. van Zyl, U. Egertsdotter, R.R. Sederoff, and R. Grene. 2003. Photosynthetic acclimation is reflected in specific patterns of gene expression in drought-stressed loblolly pine. Plant Physiol. 133:1702-1716.

$\mathrm{Xu}, \mathrm{H}$., L. Gauthier, and A. Gosselin. 1997. Greenhouse tomato photosynthetic acclimation to water deficit and response to salt accumulation in the substrate. J. Jpn. Soc. Hort. Sci. 65:777-784.

Yamaguchi, S. and Y. Kamiya. 2000. Gibberellin biosynthesis: Its regulation by endogenous and environmental signals. Plant Cell Physiol. 41:251-257.

Zeevaart, J.A., D.A. Gage, and M. Talon. 1993. Gibberellin A1 is required for stem elongation in spinach. Proc. Natl. Acad. Sci. USA 90:7401-7405.

Zawaski, C. and V.B. Busov. 2014. Roles of gibberellin catabolism and signaling in growth and physiological response to drought and short-day photoperiods in populous trees. PLoS One 9:1-12.

Zhao, M., F. Li, Y. Fang, Q. Gao, and W. Wang. 2011. Expansinregulated cell elongation is involved in the drought tolerance in wheat. Protoplasma 248:313-323.

Zhou, Y. and S.J.R. Underhill. 2015. Breadfruit (Artocarpus altilis) gibberellin 2-oxidase genes in stem elongation and abiotic stress response. Plant Physiol. Biochem. 98:81-88. 
Supplemental Table 1. Primer sequences used for quantitative RT-PCR analysis.

\begin{tabular}{|c|c|c|}
\hline Gene & Forward primer & Reverse primer \\
\hline SlGA2ox2 & 5'-ACTCGAATCCGAAGCCATCA-3' & 5'-AGGATGTGTTCGACCCGACC-3' \\
\hline SlGA2ox3 & 5'-TTTTCGCGTCCCGTCTCTGA-3' & 5'-ACCGAGCTGAAAGTAGAAGGGT-3' \\
\hline SlGA2ox4 & 5' -TGCCATCACTAATGGAAGGAAAAGACAGT-3' & 5'-ACGAGTCCTTCCTAAAGAGTCGGAT-3' \\
\hline SlGA3ox2 & 5' -AAGCTAGCGGGAAGATTAATGGGT-3' & 5'-CGGACAAGCCGGGTAAGAATTTAGT-3' \\
\hline SlGA20ox 1 & 5'-TACTATCCACCATGCCAGAAACCG-3' & 5'-GAAATTTGGACTGATGGAACGCCA-3' \\
\hline SlGA20ox2 & 5'-TTCTGGGATCATGGAACTCTTGGG-3' & 5' -CTGAGACGTTGTCTTGATGGAGGA-3' \\
\hline SlGA20ox4 & 5'-GCAAGCTTTCCCTTAGTGTGATGG-3' & 5'-ACAATGAGGTCCTGTCCCTAGAGT-3' \\
\hline$D E L L A / G A I$ & 5'-GTATGCAATGGCCTGCACTTATGC-3' & 5'-CCATCCAACTTGTTGCAAGGCATC-3' \\
\hline Actin & 5'-ATGAGTCTGGTCCTTCCATTGTCC-3' & 5'-ACCACCAAACTTCTCCATCCCATC-3' \\
\hline Tubulin & 5'-TGGATCTGGCATGGGAACACTACT-3' & 5'-ACATTCATCGGCATTCTCCACCAA-3' \\
\hline LeEXP1 & 5'-ACTCTGGTGGTTCATGGGAAACTG-3' & 5'-AGTTCAAAACAGGCTCCACAACTTA-3' \\
\hline LeEXP2 & 5'-AATGCAGCTCAATGGTGTCTCCAA-3' & 5'-CAGGGCACCCTTCGAAAAGATACA-3' \\
\hline
\end{tabular}

